\title{
Association between the reasons for and time spent doing physical activity, two variables with little relationship. An approach from the Eurobarometer Survey.
}

\author{
Domínguez-Amorós, M. ${ }^{1}$ and Aparicio-Chueca, P. ${ }^{2}{ }^{*}$ \\ 1 University of Barcelona; mariusdominguez@ub.edu \\ 2 University of Barcelona; pilaraparicio@ub.edu \\ * Correspondence: pilaraparicio@ub.edu
}

\begin{abstract}
Low levels of physical activity (PA) and sedentarism are associated with the onset of different pathologies and health problems. Regular physical activity has been linked with being beneficial to the health of the general population. Within this framework of analysis, the aim of the present study is to analyse the existing association between the time spent doing physical activity and the expressed motives for doing so, from which the first innovative aspect of the paper emerges: the use of the time spent doing PA as a study variable of the phenomenon. The data analysed come from the latest special Eurobarometer survey about the sport and physical activity done in Europe. Using an exploratory factorial analysis and a structural equations model, we were able to find a sixdimensional factorial model that explains the reasons for doing PA, demonstrating that there is no relationship between the reasons for and time spent doing PA. Therefore, motivation is not a variable that explains the time spent doing PA and another type of variable must be used to explain the phenomenon if PA is to be incentivised.
\end{abstract}

Keywords: physical activity; active live; motivational factors; health; Europe; structural equation modelling

\section{Introduction}

One of the health goals of all advanced societies is to increase PA among the population, with effective policies and strategies designed as much to stimulate PA as to overcome the obstacles that impede it. As the basis for the design of these strategies and policies, different authors have highlighted the need to know the patterns of PA among the population, in addition to the factors and reasons that lead an individual to begin to do PA and to keep it up or give it up [1-4].

Doing physical activity has become an increasingly important social issue in recent decades because, among other reasons, physical inactivity and sedentary lifestyles have contributed to the growing prevalence of pathologies such as obesity, diabetes mellitus, heart disease, hypertension, and cerebrovascular accidents, nowadays the scourge of modern societies [5]

Low levels of PA and sedentarism have been associated with the onset of different pathologies and health problems [6-7]. Numerous studies have demonstrated that doing regular PA is beneficial for body composition [8-10], bone health [11-12], psychological health and stress [13-14], and cardiorespiratory capacity, among others [15-18]. The prevalence of these illnesses is still increasing, leading to greater morbidity and mortality, and the consequent the urgent need to implement effective PA programmes to reduce the sedentary behaviour of the population [19].

In this paper, physical exercise is defined as a physical activity that is done with a specific aim [20]. In other words, the activity is pre-planned and organised to improve or maintain one or more 
aspects that determine an individual's physical condition [21-23]. Regular exercise is one of the main instruments available to the population to promote and maintain good health. Motivation is considered to be a process that "stimulates and directs behaviour towards the aim or goal of an activity that is instigated and sustained, while obstacles are understood as barriers or impediments that lead to not doing an activity, and which therefore have a fundamental impact on starting and consolidating PA habits" [20, 24-25].

Many studies in recent years have uncovered a multitude of motivational factors that directly or indirectly intervene in people's interest and participation in physical exercise. Regarding the variables that generate motivation, [22-23] point to having fun and occupying free time, maintaining physical fitness and appearance, health, and an enjoyment of sports, in that order, as the main reasons why people do physical exercise in their free time.

The study of the reasons for doing PA can be approached from different perspectives. A first group of studies analyse the association between motivational factors and sociographic variables and lifestyles (gender differences, adolescents, university students, retired people, etc.) [26-30]. A second group focus on analysing the reasons for doing PA in a specific city or country [31-37]. And a third and last group relate the reason for doing the PA with health. In this case, they seek to establish relationships between chronic illnesses such as diabetes, obesity, and cancer, among others, and motivation [38-44]. The present study wants to add a new analysis group, relating motivation with the time spent doing PA. This is a well-used line in other areas of social science studies but has so far not been developed in the field of sport.

The study of the time spent doing PA is of interest because it contributes a new variable to the study of PA, even though it is one that is already used in other branches of the social sciences. Within this analysis framework, the general aim of the study is to analyse the existing relationship between the time spent doing PA (either moderate or vigorous) and the expressed reasons for doing so, the importance of which is rooted in improving the analysis of the phenomenon, thus increasing knowledge about PA to be able to effectively promote its performance and improve the health of society.

\section{Materials and Methods}

\subsection{Data}

The data analysed come from the special Eurobarometer on sport and physical activity carried out by the European Union in all 28 of its member states. The last edition was presented in December 2017 [45]. The database is comprised of the information given face-to-face by 28,031 individuals. It is a representative sample of all the European countries with the individuals selected having done PA in the previous week stating that they do either moderate or vigorous PA, in addition to reporting the time spent doing both. The subsample is comprised of 9,404 individuals.

The Eurobarometer survey focuses on 7 different areas related to physical activity: frequency, intensity, time spent doing it, place where citizens do PA, motives for and obstacles to doing PA, voluntary participation in PA, and how they perceive the policies implemented by the local government regarding doing physical activity in their local area.

Table 1. Socio-demographic characteristics of the subsample that does moderate and vigorous PA.

\begin{tabular}{cl}
\hline Variables & Percent \\
\hline Gender & \\
Men & 52.5 \\
Women & 47.5 \\
\hline Age (Mean) & 46,75 \\
$15-24$ years & 11.9 \\
25 - 39 years & 25.7 \\
40 - 54 years & 26.2 \\
\hline
\end{tabular}




\begin{tabular}{|c|c|}
\hline 55 years and older & 36.2 \\
\hline \multicolumn{2}{|l|}{ Marital status } \\
\hline Unmarried & 20.4 \\
\hline (Re-)Married/Single with partner & 66.3 \\
\hline Divorced or separated & 6.9 \\
\hline Widowed & 5.4 \\
\hline Other & .9 \\
\hline Refusal & .2 \\
\hline \multicolumn{2}{|l|}{ Age education } \\
\hline Up to 15 years & 8.1 \\
\hline $16-19$ & 40.9 \\
\hline 20 years and older & 40.8 \\
\hline Still studying & 8.8 \\
\hline No full-time education & .3 \\
\hline Refusal & .1 \\
\hline \multicolumn{2}{|l|}{ Respondent occupation scale } \\
\hline Self-employed & 9.3 \\
\hline Managers & 14.6 \\
\hline Other white-collar workers & 13.3 \\
\hline Manual workers & 22.8 \\
\hline House persons & 3.1 \\
\hline Unemployed & 5.2 \\
\hline Retired & 22.9 \\
\hline Students & 8.8 \\
\hline \multicolumn{2}{|l|}{ Type of community } \\
\hline Rural area or village & 30.0 \\
\hline Small/medium-sized town & 42.5 \\
\hline Large town & 27.4 \\
\hline \multicolumn{2}{|l|}{ Social class - self-assessment } \\
\hline Working class & 19.6 \\
\hline Lower middle class & 12.8 \\
\hline Middle class & 52.4 \\
\hline Upper middle class & 11.3 \\
\hline Higher class & 1.1 \\
\hline Other & .1 \\
\hline None & .8 \\
\hline Refusal & .5 \\
\hline
\end{tabular}

\subsection{Measures}

At the methodological level, this paper uses two different groups of variables. The first group is comprised of all the variables related to the time Europeans spend doing PA. The second group is made up of the variables related to the reasons for doing PA.

Regarding the first group of variables (the dependent variables of the analysis performed), one of the key elements and a topic of debate in the scientific community is the operationalisation of the measurement of PA. While some authors state that the most objective way of measuring PA is by monitoring heart rate using accelerometers, pedometers, or indirect calorimetry, others affirm that self-reporting methods or questionnaires are sufficient [46-50]. One of the instruments used to measure regular physical activity is the International Physical Activity Questionnaire (IAPQ) [51-52].

Both methods to operationalise and calculate physical activity levels involve technical difficulties and are highly costly in terms of the fieldwork required to carry out international level comparative studies, and this is not their specific objective. Therefore, there are no European-level studies that use these methodologies. 
The special Eurobarometer on sport and physical activity is still the tool most used in other major public opinion social surveys. It collects data about the frequency (days per week) and minutes per day that Europeans do PA, differentiating between moderate and vigorous PA [53]. The proposed calculation method in this study is the operationalisation of the time spent doing PA in minutes per week, multiplying the frequency of doing PA in days per week by the minutes per day spent on moderate or vigorous physical activity. Europeans spend an average of 223.34 minutes per week doing vigorous PA and 245 minutes per week doing moderate PA (Table 2).

Table 2: Statistics of the time spent doing PA (minutes per week). Subsample of individuals that do vigorous and moderate PA

\begin{tabular}{lcc}
\hline & Vigorous PA & Moderate PA \\
\hline Average number of minutes of PA/week & 223.34 & 244.84 \\
\hline Standard deviation & 205.16 & 216.34 \\
\hline Average number of minutes of PA/day & 64.82 & 61.26 \\
\hline
\end{tabular}

In the case of the time variable moderate and vigorous PA, we worked with logarithmic transformation due to not meeting the assumptions of normality and linearity. The possible existence of univariate and multivariate atypical values was also checked by means of standard normal deviations such as the Mahalanobis distance.

Among the second large group of variables to analyse, which correspond to the independent variables, there are those related to the reasons Europeans give for doing PA. In this case, and as a closed-ended question, those surveyed were asked directly about their most usual reasons for doing sport and PA. This multi-response question was transformed into dummy variables, one for each reason, and the items with a response level below 5\% were discarded.

The most given reason why respondents did PA was to improve their health (58.73\%), followed by for fitness (52.26\%). Other popular reasons with percentages with response rates of between 30 and $40 \%$ were to relax, to improve their physical performance, to have fun, and to control their weight. Table 3 shows the descriptive statistics of the reasons given, together with the average time spent doing either vigorous or moderate PA. The results show that the most time spent doing both moderate and vigorous PA is when it is being done to learn new skills and to improve self-esteem

Table 3. Statistics for the time spent doing vigorous or moderate PA (minutes per week) according to the reason for doing it. Subsample of subjects that did vigorous or moderate PA.

\begin{tabular}{lccc}
\hline Reason for doing PA & Percentage & $\begin{array}{c}\text { PA } \\
\text { Vigorous }\end{array}$ & Moderate \\
\hline Improve health & 58.73 & 216.60 & 239.23 \\
\hline Physical appearance & 23.35 & 216.87 & 231.16 \\
\hline Counteract aging & 21.16 & 212.71 & 241.30 \\
\hline Have fun & 33.17 & 223.09 & 248.36 \\
\hline Relax & 39.63 & 213.17 & 241.24 \\
\hline Be with friends & 22.89 & 218.01 & 239.77 \\
\hline Physical performance & 33.41 & 223.86 & 242.97 \\
\hline Fitness & 52.26 & 210.04 & 234.28 \\
\hline Control weight & 30.42 & 202.28 & 224.09 \\
\hline Self-esteem & 16.49 & 229.22 & 248.77 \\
\hline New skills & 9.70 & 249.04 & 257.46 \\
\hline
\end{tabular}

\subsection{Statistical Analysis}


First, we carried out an exploratory factorial analysis with Varimax rotation to identify the structure of the associations between the reasons given, which would then be the starting point for the confirmatory factorial model.

Second, we worked with structural equation models (SEM), using the AMOS 25 programme. In brief, with the integrated application of various methods such as confirmatory factor analysis and path analysis, the SEM is a statistical technique to assess the validity and reliability of theoretical models composed of latent constructs. Figure 1 shows the hypothesised model, consisting of two components: the measurement model, which defines six unobservable latent variables using one or more observed variables (reasons for doing PA), and the structural model, which imputes relationships between latent variables. Modelling the relationships between latent variables enables the estimated effects of the time spent doing PA to not depend on the errors of means, therefore considering the error terms and estimating the effects simultaneously. The structural part of the model considers that the reasons explain the time spent doing moderate or vigorous PA, latent observed variables based on the two time indicators, considering a relationship between their error terms.

Figure 1. Hypothesized model: measurement model and structural model

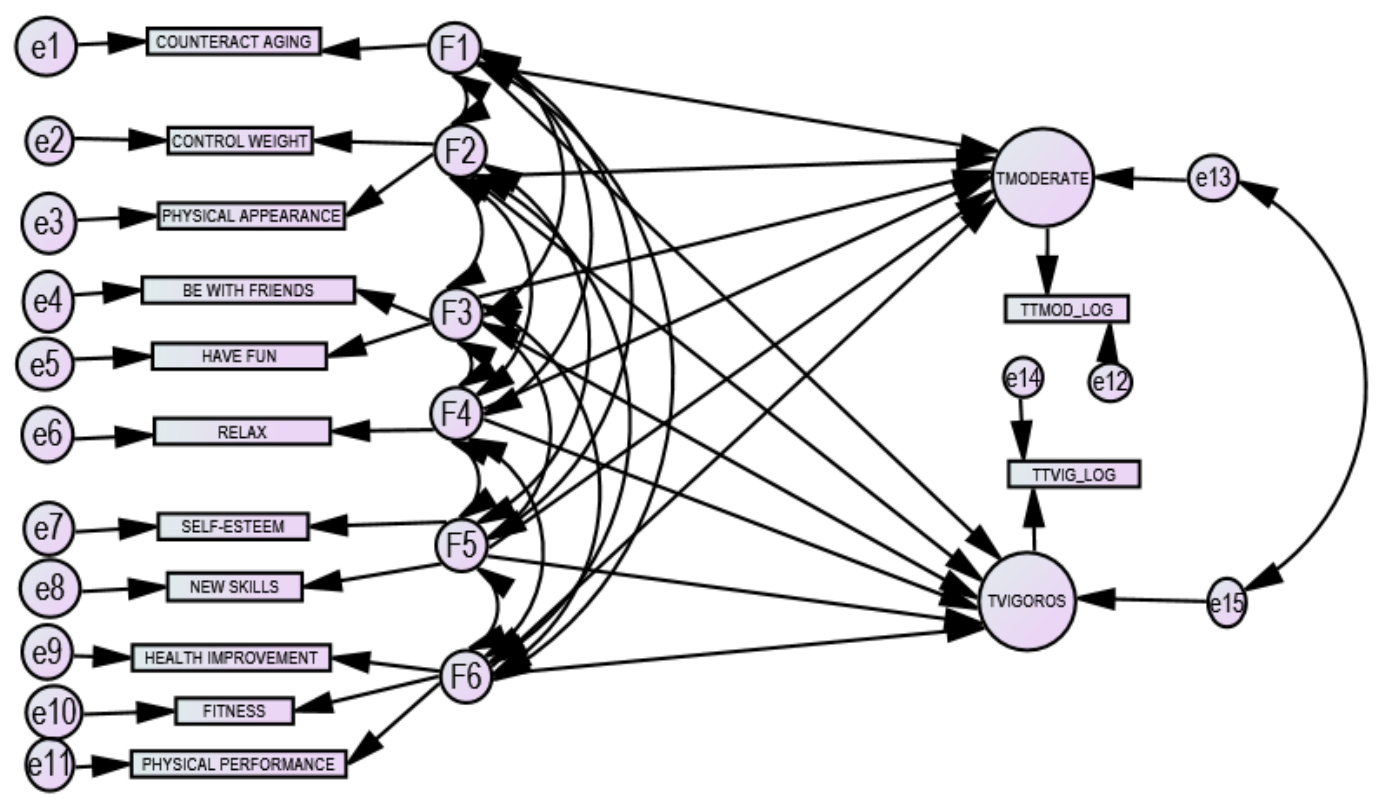

The aims of this study are twofold. First, to validate the measurement model by means of a confirmatory factorial analysis of the reasons for doing PA (the left-hand part of Figure 1): independent variables. And second, to test the structural model (the right-hand part of Figure 1) using an explicatory model, selecting the time spent doing moderate and vigorous PA as the dependent variables.

The estimation method used was the generalised least squares (GLS). Among other advantages, this method allows dichotomous variables and continuous variables that do not fit with the criteria of normality to be introduced into the analysis. It is one of the methods most used and recommended when the data do not meet the assumption of normality.

\section{Results}




\subsection{Exploratory factorial analysis with varimax rotation (Principal component analysis)}

The result of the exploratory EFA estimates the factorial structure of the reasons for doing AP in six factors or dimensions. The data corresponding to $\mathrm{KMO}$, at 0.80 , and the Barlett test with a signification of 0,000 , indicate that the factorial solution explaining $70 \%$ of the initial variance is adequate.

The factorial loads presented in Table 4 account for the structure of the rotated component matrix, showing 6 dimensions of reasons for doing moderate or vigorous PA. The first dimension contains the reasons related to fitness, health improvement, and physical performance; the second dimension includes the reasons related to physical appearance; and in the third dimension are doing PA for fun and for the social aspect. The reasons to increase skills and competence, to counteract ageing, and to relax shape dimensions 4,5 and 6, respectively. Notably, the reason to increase selfesteem is included in two of the dimensions: in dimension 2 , together with the reasons to do with physical appearance, and in dimension 4 regarding increasing skills and competence.

Table 4: Rotated components matrix of the AFC. Factors, percentage of explained variance, and factorial loads. Subsample of individuals that did moderate or vigorous FA

\begin{tabular}{|c|c|c|c|c|c|c|}
\hline & & Percent & $\begin{array}{l}\text { Factori } \\
\text { age of ex }\end{array}$ & $\begin{array}{l}\text { al loads } \\
\text { plained }\end{array}$ & variance & \\
\hline & 1 & 2 & 3 & 4 & 5 & 6 \\
\hline Motivations or reasons given for doing PA & $13.87 \%$ & $12.21 \%$ & $12.05 \%$ & $10.90 \%$ & $9.28 \%$ & $9.20 \%$ \\
\hline Fitness & .719 & & & & & \\
\hline Health improvement & .696 & & & & & .216 \\
\hline Physical performance & .642 & & & .287 & & \\
\hline Physical appearance & & .754 & & .222 & & \\
\hline Control weight & & .722 & & & .226 & \\
\hline Be with friends & & & .832 & & & \\
\hline Have fun & & & .728 & & & .233 \\
\hline New skills & & & & .831 & & \\
\hline Self-esteem & & .427 & & .580 & & \\
\hline Counteract aging & & & & & .943 & \\
\hline Relax & & & & & & .928 \\
\hline
\end{tabular}

\subsection{Structural Equation Modelling (SEM)}

\subsubsection{Measurement Model: Confirmatory Factor Analysis (CFA)}

Based on the results of the initial exploratory factorial analysis, the first research question to test if the six-factor model fits the data and if the two models have an identical structure or whether significant differences between moderate PA and vigorous PA can be identified. The second question is whether there is a significant covariance between these factors, or whether they are similar in the two models.

To meet this objective, two measurement models were developed, one for the time spent doing vigorous PA and the other for the time spent doing moderate PA. The results of the two models show that they have identical structures, and so we considered it appropriate to present a single measurement model that takes the population's reasons for doing both moderate and physical activity into account. The measurement model fits the 6 latent factors, with a Chi-square of 348,944, 31 degrees of freedom, and a p-value of less than 0.001 .

Figure 2 shows the standardized regression coefficients, the correlations among the exogenous variables, and the estimates of squared multiple correlations. 
Figure 2. Results of the measurement model. Confirmatory factor analysis.

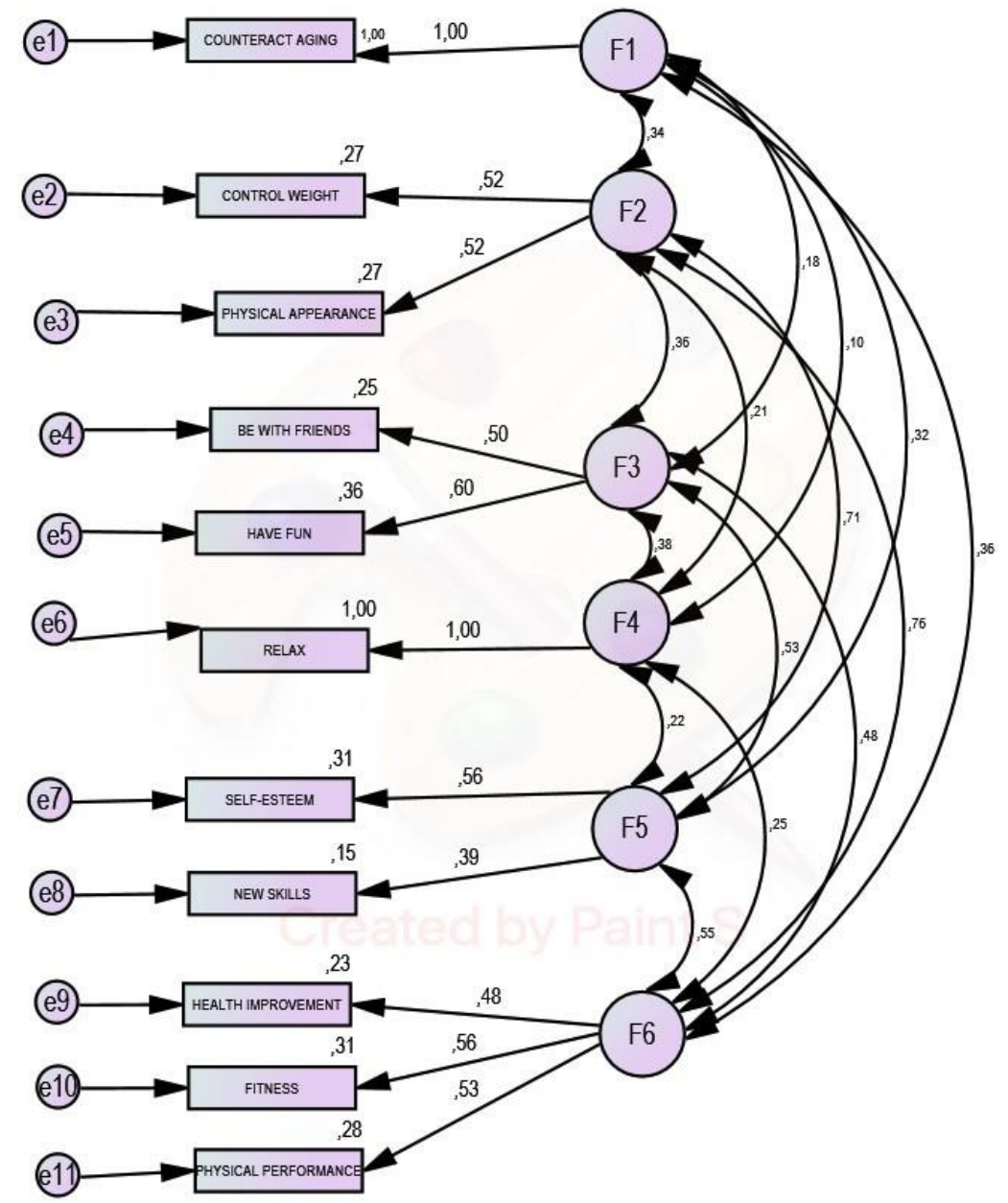

CHI $=348,944 ;$ Probability Level $=0,000 ; C F I=.912 ;$ RMSEA $=.0033$

The standardized regression coefficients and correlations among the exogenous variables are shown next to the arrows. The estimates of the squared multiple correlations are reported below the construct names. The ovals represent the latent variables and the rectangles represent the observed variables. All the regression weights are significantly different from zero at the 0.001 level. Loading is fixed at the value of 1 in the non-standardized solution

The results obtained enable us to validate the factorial structure of the measurement model based on the six latent factors identified in the previous phase. The standardised loadings for most of the items are above 0.5 , except for the reason new skills, which is also the reason given with the lowest explained variance percentage. Also worthy of note is the high correlation between the latent factors F6 (fitness and health improvement) and F2 (physical appearance), F5 (self-esteem and new skills), and F2 (physical appearance), all of which are higher than 0.50 .

\subsubsection{Structural model}

Figure 3 and Table 5 show the results of the structure model. The explanatory capacity of the reasons according to the time spent doing vigorous and moderate PA, using their latent variables, can be observed.

Figure 3. Results of the structural model. Standardized weights 
Peer-reviewed version available at Int. J. Environ. Res. Public Health 2020, 17, 6777; doi:10.3390/iierph17186777

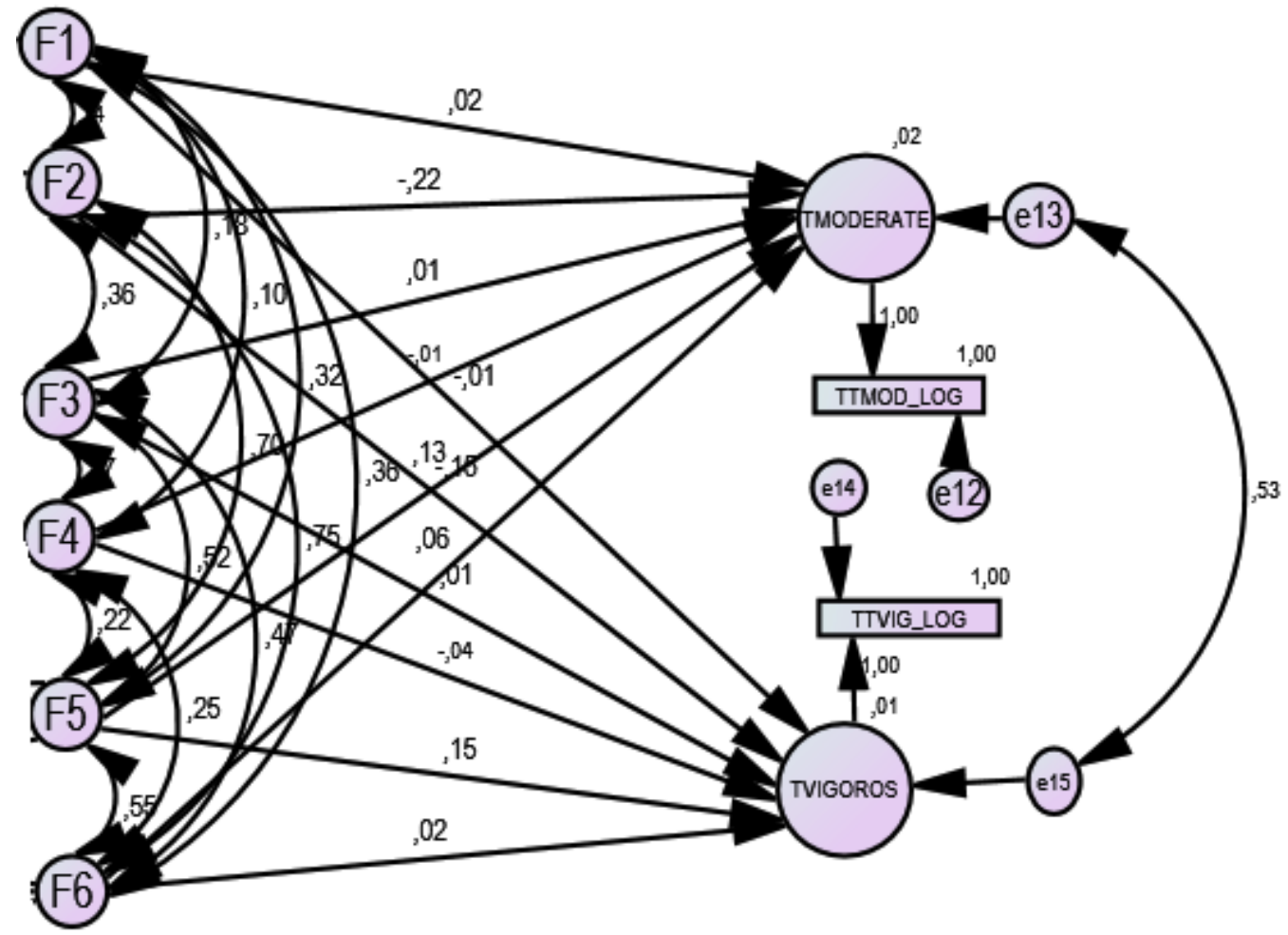

CHI $=397,260 ;$ Probability Level $=0,000 ; C F I=.942 ;$ RMSEA $=.0030$

The standardized regression coefficients are shown next to the arrows. The estimates of squared multiple correlations are reported below the construct names. The ovals represent the latent variables and the rectangles represent the observed variables. Loading fixed at the value of 1 in the non-standardized solution.

Table 5: Regression weights and standardized estimate with the p-values of the factors and the latent variables of the time spent doing PA

\begin{tabular}{cccccc}
\hline & & & Estimate & Standardized estimate & P \\
\hline Moderate time & $<---$ & F1 & .04 & .02 & .136 \\
\hline Moderate time & $<---$ & F2 & -.83 & -.22 & $* * *$ \\
\hline Moderate time & $<---$ & F3 & .04 & .01 & .760 \\
\hline Moderate time & $<---$ & F4 & -.02 & -.01 & .401 \\
\hline Moderate time & $<---$ & F5 & .59 & .13 & $* *$ \\
\hline Moderate time & $<---$ & F6 & .25 & .06 & .116 \\
\hline Vigorous time & $<---$ & F1 & -.02 & -.01 & .510 \\
\hline Vigorous time & $<---$ & F2 & -.54 & -.14 & $* * *$ \\
\hline Vigorous time & $<---$ & F3 & .05 & .01 & .682 \\
\hline Vigorous time & $<---$ & F4 & -.08 & -.04 & $* 14$ \\
\hline Vigorous time & $<---$ & F5 & .65 & .02 & $* * *$ \\
\hline Vigorous time & $<---$ & F6 & .07 & & .639 \\
\hline$* p<.05 . * * p<.01 . * * * p<.001$ & & &
\end{tabular}

The model's global fit shows that the hypothesized model fits signficantly. Moreover, the analysis of the modification indexes shows that no respecification of the model and or substantial changes in the estimated parameters can be made.

The results show that the explanatory capacity of the reasons for doing PA according to the time spent doing it is low, at approximately $2 \%$ for both types of PA. Furthermore, the estimate of the parameters of the model shows that the correlation between the error of the endogenous variables (which does not explain the time spent doing the two types of PA) is corelated (0.53). This indicates that what is not explained by the reasons for spending time spent doing PA has a shared identity with both vigorous and moderate physical activity. 
It is worth noting in particular the latent variables that have a significant effect on the time spent doing PA. For both moderate and vigorous PA, the latent factors of physical appearance and selfesteem have a significant effect on the time spent per week doing PA. Contrarily, however, while the reason physical appearance implies a reduction in the time spent doing (-0.831 and -0.544 for moderate and vigorous PA, respectively), the reasons self-estem and new skills imply an increase in the time spent doing PA (0.591 and 0.649 for moderate and vigorous PA, respectively). Futhermore, in the case of vigorous PA, the reason to relax also has the effect of reducing the time spent doing PA, although less so than physical appearance (-0.078).

\section{Discussion}

The first objective set in this study was to develop a factorial structure that reduces the number of reasons why Europeans do PA. The results show a robust factorial structure made up of 6 dimensions: fitness and health, appearance, F\&F, self-esteem, aging, and relaxation. This dimensional structure coincides with the motivational structures studied in the bibliography review [22], allowing us to create a factorial model that summarises the reasons for doing PA.

The second objective was to determine if there are two different model structures for vigorous PA and moderate PA, and if the model was sound. In other words, to identify if the motivational structure was different for people doing vigorous PA and moderate PA. As the confirmatory analysis showed, there are not two different structures and the two types of activity are explained by the same measurement model. The measurement model is robust and explains this behaviour (the correlation between the times implies that both vigorous and moderate exercise are explained by the same model).

Dimension F2, physical appearance, is highly correlated with the dimension of health and exercise. Therefore, the Europeans that state that they do PA for their appearance and to indirectly acquire new skills are also doing it for health reasons. The model also shows another correlation between the factors of appearance (F2) and self-esteem (F5). This result is to be expected since people concerned with their appearance, who do PA to improve it, are also indirectly improving their selfesteem. These correlations are important given that they can be used to re-focus policies to incentivise doing PA to not only emphasise the health aspect but also the factors of appearance and self-esteem.

The third and last objective was to analyse whether the reasons for doing PA explain the time spent doing it, either vigorously or moderately. The last structural equations model indicates that there is no relationship between them, or in other words that the analysis of the reasons for doing PA does not involve studying the time spent doing it. This finding suggests that to analyse the time spent doing PA, it would be more appropriate to relate it to other types of variables such as demographic ones, or to types of disease, among others.

We consider that incorporating the time spent doing PA into studies on PA is a new line of investigation that can help to know the phenomenon better and can better incentivise the public policies that promote doing PA, thus improving the health of the population. The time spent doing PA and the times of day must be known to create both public and private spaces that help to promote PA and, indirectly, people's health, social integration, and self-esteem.

The main imitation of the study is the way the survey was carried out, to the effect that when asked their reasons for doing PA respondents were not asked to differentiate between vigorous and moderate PA. Therefore, their self-reported reasons are for doing PA in general. Other limitations stem from the construction of the variable "time spent", and from the subsample chosen, which was made up of Europeans that do PA and who had done vigorous or moderate PA in the previous seven days.

\section{Conclusions}

Our findings are important because by studying a European database, they analyse the time spent doing PA and the reasons for doing so irrespective of age, gender, class variables, lifestyle, 
health, ethnicity, and so on. Despite the limitations, the results contribute to the literature by providing a new variable to consider within the study of PA. The main novelty of the paper is that it introduces the variable time spent doing PA, analysing the relationship between this variable and the reasons for doing PA. It seems logical to think that people who do PA for health reasons spend more time doing it. However, the results of the study contradict this main study hypothesis. There is no relationship between the reasons for doing PA and the time spent doing it.

As stated in the introduction to this paper, the analysis of the reasons for doing PA was carried out from three different perspectives. This study aims to open up a new perspective, the study of time and motivation, demonstrating that while there is no relation between them, we consider it important to introduce the time variable in studies of the other three perspectives.

\section{References}

1. Booth ML, Bauman A, Owen N, Gore CJ. Physical activity preferences, preferred sources of assistance, and perceived barriers to increased activity among physically inactive Australians. Prev Med. 1997;26(1):131-7.

2. Cohen-Mansfield J, Marx MS, Guralnik JM. Motivators and barriers to exercise in an older communitydwelling population. J Aging Phys Activ. 2003;11(2):242-53.

3. Sheppard L, Senior J, Park CH, Mockenhaupt R, Chodzko-Zajko W. Strategic priorities for increasing physical activity among adults age 50 and older: The national blueprint consensus conference summary report. J Aging Phys Activ. 2003;11(3):286-92.

4. Chodzko-Zajko W.J., Schwingel A., Romo-Pérez V. Un análisis crítico sobre las recomendaciones de actividad física en España. Gac. Sanit. 2012;26:525-533. doi: 10.1016/j.gaceta.2011.10.019. a

5. Beltrán F., Reis A., Peiró C. Actividad física y sedentarismo en adolescentes de la Comunidad Valenciana. Int. Med. Sci. Phys. Act. Sport. 2012;12:123-137.

6. Hu, F. B., Li, T. Y., Colditz, G. A., Willett, W. C., \& Manson, J. E. Television watching and other sedentary behaviors in relation to risk of obesity and type 2 diabetes mellitus in women. Jama, 2003; 289(14), 1785-1791.

7. Warren, T. Y., Barry, V., Hooker, S. P., Sui, X., Church, T. S., \& Blair, S. N. Sedentary behaviors increase risk of cardiovascular disease mortality in men. Medicine and science in sports and exercise, 2010;42(5), 879 .

8. Laguna, M., Ruiz, J. R., Gallardo, C., García-Pastor, T., Lara, M. T., \& Aznar, S. Obesity and physical activity patterns in children and adolescents. Journal of pediatrics and child health, 2013, 49(11), 942-949.

9. Hafner, M., Pollard, J., \& Van Stolk, C. (2018). Incentives and physical activity: An assessment of the association between Vitality's Active Rewards with Apple Watch benefit and sustained physical activity improvements.

10. King, D., Hume, P. A., Hardaker, N., Cummins, C., Gissane, C., \& Clark, T. Sports-related injuries in New Zealand: National Insurance (Accident Compensation Corporation) claims for five sporting codes from 2012 to 2016. British journal of sports medicine, 2019;53(16), 1026-1033.

11. Gomez-Bruton, A., Montero-Marin, J., González-Agüero, A., Garcia-Campayo, J., Moreno, L. A., Casajus, J. A., \& Vicente-Rodriguez, G. The effect of swimming during childhood and adolescence on bone mineral density: a systematic review and meta-analysis. Sports Medicine, 2016;46(3), 365-379

12. Lozano-Berges, G., Matute-Llorente, Á., González-Agüero, A., Gómez-Bruton, A., Gómez-Cabello, A., Vicente-Rodriguez, G., \& Casajús, J. A. Soccer helps build strong bones during growth: a systematic review and meta-analysis. European journal of pediatrics, 2018;177(3), 295-310.

13. Stults-Kolehmainen, M. A., Lu, T., Ciccolo, J. T., Bartholomew, J. B., Brotnow, L., \& Sinha, R. Higher chronic psychological stress is associated with blunted affective responses to strenuous resistance exercise: RPE, pleasure, pain. Psychology of Sport and Exercise, 2016;22, 27-36.

14. Brockmann, A.N., Ross, K.M. Bidirectional association between stress and physical activity in adults with overweight and obesity. Journal of Behavioral Medicine, 2020, 43, 246-253. https://doi.org/10.1007/s10865-020-00145-2

15. Fuchs, R., Wunsch, K., \& Klaperski, S. 11 Emotionen und Stress. Sportpsychologie: Ein Lehrbuch, 2020,246. 
16. Loprinzi, P. D., Cardinal, B. J., Cardinal, M. K., \& Corbin, C. B. Physical education and sport: Does participation relate to physical activity patterns, observed fitness, and personal attitudes and beliefs? American Journal of Health Promotion, 2018;32(3), 613-620.

17. Kim, M., \& Cardinal, B. J. A review of how physical activity education policies in higher education affect college students' physical activity behavior and motivation. International Journal of Human Movement Science, 2016;10(2), 41-51.

18. Mayorga-Vega, D., Saldías, M. P., \& Viciana, J. Condición física, actividad física, conducta sedentaria y predictores psicológicos en adolescentes chilenos: diferencias por género.(Physical fitness, physical activity, sedentary behavior and psychological predictors in Chilean adolescents: Differences by gender). Cultura, Ciencia y Deporte, 2019;14(42), 233-241.

19. Chin, S. H., Kahathuduwa, C., \& Binks, M. Is sedentary behaviour unhealthy and if so, does reducing it improve this?. International Journal of Clinical Practice, 2017,71(2), e12925. doi: 10.1111/ijcp.12925.

20. Portela-Pino, I.; López-Castedo, A.; Martínez-Patiño, M.J.; Valverde-Esteve, T.; Domínguez-Alonso, J. Gender Differences in Motivation and Barriers for The Practice of Physical Exercise in Adolescence. International Journal of Environmental Research and Public Health, 2020;17, 168.

21. Chodzko-Zajko, W.J.; Schwingel, A.; Romo-Pérez, V. Un análisis crítico sobre las recomendaciones de actividad física en España. Gac. Sanit. 2012;26, 525-533.

22. Rodríguez-Romo, G.; Boned-Pascual, C.; Garrido-Muñoz, M. Motivos y barreras para hacer ejercicio y practicar deportes en Madrid. Rev. Panam. Salud Pública 2009;26,244-254. doi: 10.1590/S102049892009000900009

23. Ríos, D., Cubedo, M. \& Ríos, M. Graphical study of reasons for engagement in physical activity in European Union. SpringerPlus 2013;2, 488. https://doi.org/10.1186/2193-1801-2-488

24. Menéndez-Balaña, F.J. Introducción al estudio de la psicología de la motivación. In Psicología de La Motivación; Teoría y Práctica (1-63); Sánchez y Torres: Madrid, Spain, 2013.

25. Bauman, A.E.; Reis, R.S.; Sallis, J.F.; Wells, J.C.; Loos, R.J.; Martin, B.W. Correlates of physical activity: Why are some people physically active and others not? Lancet 2012;380, 258-271.

26. Rodriguez Montero, A., Morera, M., Barrantes Brais, K., \& Ugalde Ramírez, J. A. Relación entre los Factores Motivacionales, la Edad y el Sexo en las Personas Participantes de un Proyecto de Natación. MHSalud: Revista En Ciencias Del Movimiento Humano Y Salud, 2014;11(1). https://doi.org/10.15359/mhs.11-1.2

27. Escribano, L. G., Fernández-Marcote, A. E., Casas, A. G., López, P. J. T., \& Marcos, M. L. T. Revisión y análisis de la influencia del entorno afectivo y los motivos de práctica de actividad física actual en adolescentes. Journal of Negative and No Positive Results: JONNPR, 2017;2(1), 23-28.

28. Otero-Wandurraga, J. A., Cohen, D. D., Delgado-Chinchilla, D. M., Camacho-López, P. A., AmadorAriza, M. A., Rueda-Quijano, S. M., \& López-Jaramillo, J. P. Perceived facilitators and barriers to physical activity in adolescents in Piedecuesta (Santander), in 2016: qualitative analysis. Revista Facultad Nacional de Salud Pública, 2020;38(2).

29. Bover, M. B., Arnal, R. B., Llario, M. G., Miravet, M. E., \& Galdón, M. L. F.. Motivaciones para el ejercicio físico y su relación con la salud mental y física: un análisis desde el género. Revista INFAD de Psicología. International Journal of Developmental and Educational Psychology., 2020;1(1), 351-360.

30. Kleppang, A. L., Thurston, M., Hartz, I., \& Hagquist, C. Psychological distress among Norwegian adolescents: changes between 2001 and 2009 and associations with leisure time physical activity and screen-based sedentary behaviour. Scandinavian journal of public health, 2019;47(2), 166-173.

31. Hellín, P., Moreno, J. A., \& Rodríguez, P. L. Motivos de práctica físico-deportiva en la Región de Murcia. Cuadernos de psicología del deporte, 2004;4.

32. Daw, M. D. J. M., De la Torre Díaz, M. L., Seáñez, E. H., Rentería, J. B. P., \& Duarte, M. M. Motivos para la práctica de actividad física recreativa e inactividad en la población de Chihuahua (México). Nutrición clínica y dietética hospitalaria, 2016;36(1), 10-16.

33. Juan, F. R., Montes, M. E. G., \& Suárez, A. D. Análisis de las motivaciones de práctica de actividad física y de abandono deportivo en la Ciudad de La Habana (Cuba). Anales de PsicologíalAnnals of Psychology, 2007;23(1), 152-166.

34. Sandoval, J. R. G. Barreras para la práctica del ejercicio físico en estudiantes mexicanos. Sinergias educativas, 2020;5(2), 208-222.

35. Arrebola, I. A., Ortells, L. G., Estrada, A. C. M., Medina, M. M., \& Vera, J. G. Frecuencia de práctica y motivos de participación en actividades físicas en función de la etnia en escolares de 13-14 años de melilla. Retos, 2020;39,148-154.

36. Jacobo, A. B. Motivos que llevan a realizar actividad física en personas adultas del estado de Sonora, México. Pensamiento Actual, 2020;20(34). 
37. Vilugrón, G. A. F., \& Hernández, R. I. L. Motivaciones hacia la práctica de actividad física-deportiva en estudiantes de La Araucanía. Ciencias de la Actividad Física UCM, 2019;20(2), 1-13.

38. Ramírez-Vélez, R., Triana-Reina, H. R., Carrillo, H. A., \& Ramos-Sepúlveda, J. A. Percepción de barreras para la práctica de la actividad física y obesidad abdominal en universitarios de Colombia. Nutrición Hospitalaria, 2016;33(6), 1317-1323.

39. López, P. G., Gisladóttir, T., \& Ries, F. Adherencia a la Dieta Mediterránea, Motivos para la Práctica de Ejercicio Físico y Composición Corporal en Adolescentes Islandeses. Retos: nuevas tendencias en educación física, deporte y recreación, 2020;(38), 552-559.

40. Matthews, C. E., Moore, S. C., Arem, H., Cook, M. B., Trabert, B., Håkansson, N., ... \& Milne, R. L. Amount and intensity of leisure-time physical activity and lower cancer risk. Journal of Clinical Oncology, 2020;38(7), 686.

41. Chemtob, K., Rocchi, M., Arbour-Nicitopoulos, K., Kairy, D., Fillion, B., \& Sweet, S. N. Using telehealth to enhance motivation, leisure time physical activity, and quality of life in adults with spinal cord injury: A self-determination theory-based pilot randomized control trial. Psychology of Sport and Exercise, 2019;43, 243-252.

42. Vaquero-Cristóbal, R., Alacid, F., Muyor, J. M., \& López-Miñarro, P. Á. Imagen corporal: revisión bibliográfica. Nutrición hospitalaria, 2013;28(1), 27-35.

43. Guevara Sánchez, D. A. Niveles de actividad física, factores motivacionales y barreras percibidas por los pacientes con enfermedades crónicas no transmisibles de la Unidad Médica Eloy Alfaro del IESS, Quito 2019.

44. Brandão, A., Frontini, R., Peixoto, D., Fernandes, D., \& Clemente, F. M. Comparación de factores motivacionales entre la práctica de deportes de naturaleza, aventura competitiva y ocio. SPORT TKRevista EuroAmericana de Ciencias del Deporte, 2020;15-20.

45. Directorate-General for Communication. European Comission. 2017. Eurobarometer on sport and physical activity, 2017. Special Eurobarometer. 472. European Union Open Data Portal http://data.europa.eu/88u/dataset/S2164_88_4_472_ENG.

46. Montoye, H. J., Kemper, H. C. G., Saris, W. H. M., \& Washburn, R. A. Measuring Physical Activity and Energy Expenditure. Champaign, IL: Human Kinetics. 1996.

47. Smith, G. L., Banting, L., Eime, R., O'Sullivan, G., \& Van Uffelen, J. G. The association between social support and physical activity in older adults: a systematic review. International Journal of Behavioral Nutrition and Physical Activity, 2017;14(1), 56.

48. Kohl, H. W. III, Fulton, J. E., \& Caspersen, C. J. Assessment of physical activity among children and adolescents: A review and synthesis. Preventive Medicine, 2000;31(2), S54-S76

49. Welk, G. J., Corbin, C. B., \& Dale, D. Measurement issues in the assessment of physical activity in children. Research Quarterly for Exercise and Sport, 2000;71(Suppl. 2), S59-S73

50. Aparicio-Ugarriza, R., Aznar, S., Mielgoayuso, J., Benito, P. J., Pedrerochamizo, R., Ara, I., \& GonzálezGross, M. Estimación de la actividad física en población general: métodos instrumentales y nuevas tecnologías. Rev Esp Nutr Comunitaria, 2015;21(Supl 1), 215-24

51. Craig, C.L., Marshall, A.L., Sjöström, M., Bauman, A.E., Booth, M.L., Ainsworth, B.E., Pratt, M., Ekelund, U., Yngve, A., Sallis, J.F. y Oja, P. International Physical Activity Questionnaire: 12-Country Reliability and Validity. Med. Sci. Sports Exerc, 2003; 35 (8), 1381-1395

52. Minetto, M. A., Motta, G., Gorji, N. E., Lucini, D., Biolo, G., Pigozzi, F., ... \& Maffiuletti, N. A.. Reproducibility and validity of the Italian version of the International Physical Activity Questionnaire in obese and diabetic patients. Journal of endocrinological investigation, 2018;41(3), 343-349.

53. Burton NW, Turrell G, Oldenburg B, Sallis JF. The relative contributions of psychological, social, and environmental variables to explain participation in walking, moderate, and vigorous-intensity leisuretime physical activity. J Phys Activ Health. 2005;2(2):181-96 